\title{
Monetary Value of Live Trade in a Commonly Traded Primate, the Long-Tailed Macaque, Based on Global Trade Statistics
}

\author{
Malene Friis Hansen ${ }^{1,2,3 *}$, Mike Gill ${ }^{3,4}$, Elodie Floriane Briefer ${ }^{1,3 *}$, Daniel R. K. Nielsen ${ }^{3}$ and \\ Vincent Nijman ${ }^{2,3}$ \\ ${ }^{1}$ Behavioural Ecology Group, Section for Ecology and Evolution, University of Copenhagen, Copenhagen, Denmark, ${ }^{2}$ Oxford \\ Wildlife Trade Research Group, Department of Social Sciences, Oxford Brookes University, Oxford, United Kingdom, ${ }^{3}$ The \\ Long-Tailed Macaque Project, Copenhagen, Denmark, ${ }^{4}$ Technological Primates Research Group, Max Planck Institute for \\ Evolutionary Anthropology, Leipzig, Germany
}

\section{OPEN ACCESS}

Edited by:

Govindhaswamy Umapathy, Centre for Cellular and Molecular Biology (CCMB), India

Reviewed by: Jessica Bell Rizzolo, Michigan State University,

United States

Carles Vila,

Doñana Biological Station, Spanish National Research Council

(CS/C), Spain

${ }^{*}$ Correspondence:

Malene Friis Hansen malenefriishansen@gmail.com

Elodie Floriane Briefer

elodie.briefer@bio.ku.dk

Specialty section: This article was submitted to

Animal Conservation,

a section of the journal

Frontiers in Conservation Science

Received: 19 December 2021

Accepted: 20 January 2022

Published: 14 February 2022

Citation:

Hansen MF, Gill M, Briefer EF, Nielsen DRK and Nijman V (2022) Monetary Value of Live Trade in a Commonly Traded Primate, the Long-Tailed Macaque, Based on

Global Trade Statistics.

Front. Conserv. Sci. 3:839131. doi: $10.3389 /$ fcosc. 2022.839131
Non-human primates (primates) are regarded as key research subjects for pre-clinical trials of several drugs aimed to alleviate human suffering. It has long been suggested that the predominant species in the international trade in live primates for use in research is the long-tailed macaque (Macaca fascicularis). However, little is still known about the value of this international trade. Whilst the international trade to supply the requirement for biomedical testing is known to encourage illegal wildlife trade, we lack a detailed understanding of the overall value and magnitude of this trade. Such information is vital to facilitate the design of effective conservation strategies in range countries, in order to mitigate the exploitation of wild populations by organized crime networks. Here, data from CITES and the UN Comtrade databases were combined to calculate the value of this trade. We also compared the number of individual primates traded as reported in the two databases to investigate possible correlations. Results show that, from 2010 to 2019, the international trade in long-tailed macaques constituted a market worth of US \$1.25 billion. We found a positive correlation between individual primates traded in the UN Comtrade Database and individual long-tailed macaques reported in the CITES Trade Database, suggesting that we can use the UN Comtrade database to investigate values and magnitude of the international legal trade in wildlife, and that legal trade in live primates is primarily constituted of long-tailed macaques alone.

Keywords: biomedical research, conservation, international trade, illegal trade, legal trade, Macaca fascicularis, pre-clinical testing, price

\section{INTRODUCTION}

The international primate trade is considered to have peaked in the 1960s, with India alone exporting 50,000 live wild primates per annum (Nijman et al., 2011). However, four decades later, the legal and illegal trade in primates remains a serious threat to primates species (Nijman and Healy, 2016; Estrada et al., 2017), and the predominant species traded is thought to be the long-tailed macaque (Macaca fascicularis).

Despite genuine efforts to reduce the use of live non-human primates in research in the twenty-first century, species such as the long-tailed macaque are still utilized in biomedical 
procedures and pre-clinical testing (Home Office, 2017). While the majority of individuals in trade are first, second or higher generation offspring of captive long-tailed macaques, the overall trade does affect the management and conservation of the species in the Southeast Asian range countries (Hansen et al., 2021). Little is known about the magnitude and monetary value of the international trade in long-tailed macaques, which can lead to overexploitation of wild populations if left unexamined (Andersson et al., 2021). The US is a main importer of longtailed macaques (CITES Trade Database, 2021), and in 2020, Tittensor et al. found a positive correlation between legal imports and confiscations in the US, suggesting that legal trade and illegal trade goes hand in hand.

There is a need for specific data both globally and by country regarding the volume and value of the international trade in longtailed macaques as the $21^{\text {st }}$ century progresses, and especially given the emergence of China as a one stop shop for breeding and research (Cyranoski, 2016), and the efforts by scientists to adopt $3 \mathrm{R}$ based approaches that seek to replace, reduce and refine the use of live animals in research (Guhad, 2005; Badyal et al., 2009; Wells, 2011; Prior et al., 2017). In addition, we need to understand how the trade in long-tailed macaques has been affected by the requirements for pre-clinical trials related to vaccines (Lankau et al., 2014). This quantity and pricing data is crucial to inform work regarding both the illegal and legal trade in this species, and to increase conservation efforts to minimize the exploitation of wild long-tailed macaques.

Here, we combine data from the Convention for International Trade in Endangered Species of Wild Fauna and Flora (CITES) Trade Database, which provides data on trade on species listed in the appendices of the Convention (CITES Trade Database, 2021), with that of the United Nations Commodity Trade Statistics (UN Comtrade) Database, which provides data regarding international trade in a wide range of commodities (UN Comtrade, 2021). The former database includes data on international trade at the species level (including long-tailed macaques) and their source (e.g. wild-caught or captive-bred) but it does not give monetary values. The latter database includes data at an aggregate level (e.g., all species of primates combined) to which it attaches a monetary value. Arguably, reporting animal species at Class level makes it difficult to fully comprehend and monitor the trade (Chan et al., 2015). However, for those countries that export one or a very limited number of species of a particular taxon, and in cases where this or these species are listed on one of the appendices of CITES, it may be possible to combine both databases to obtain a more accurate insight into the trade. For instance, Nijman (2017) focused on the export of eels from North Africa and combined data for the European eel Anguilla anguilla, the only species of eel listed on CITES and the only species of eel to occur in North Africa. Using both datasets, he was able to estimate levels of trade, establish its monetary value and investigate how this was related to the importing regions to ultimately make recommendations on how to better regulate the trade in European eel. The UN Comtrade Database has also been used to quantify the amount and the value of the shark fin trade combined with the CITES Trade Database to understand the specific species traded (Fowler et al., 2021).
In this study, researchers focused on identifying the trade flows and main importers to pin point the geographical areas, where specific shark species are in need of conservation efforts (Fowler et al., 2021).

Here, we follow a similar approach to Nijman (2017) and Fowler et al. (2021), in order to gain insights into the international trade in live long-tailed macaques, primarily for biomedical use. The validity of this approach hinges, firstly, on a strong level of agreement between trade flows between the countries involved in the live primate trade, and secondly, on a high level of concordance between the numbers of live primates and live long-tailed macaques reported by individual countries on a year-by-year basis.

The aim of this study was to establish if there is a correlation between the quantities of live long-tailed macaques reported in the CITES Database and the quantities reported for live primates in the UN Comtrade Database. If this is the case, this would then enable the average unit value obtained from UN Comtrade data to be applied to the quantities of macaques reported by CITES parties in the same period. It will furthermore show if the long-tailed macaque is in fact the predominant primate species traded.

\section{METHODS}

We focused on the period 2010 to 2019, inclusive, as data from 2020 or 2021 were not yet available. For both databases, we focused on live trade as reported by the exporting country [HS code 010611, live primates, in the UN Comtrade Database (UN Comtrade Database 2021)]. We included re-exports as reported in the CITES Trade Database (CITES Trade Database, 2021), since these were also included in the UN Comtrade Database.

The CITES Trade Database revealed that $95.6 \%$ of exports of live long-tailed macaques originated from the following eight countries: Cambodia, China, Indonesia, Laos, Mauritius, The Philippines, Thailand, and Vietnam. Long-tailed macaque range countries, Singapore, Malaysia, Timor Leste, and Brunei Darussalam did not report any international trade over this time period, which was confirmed through communication with in-country researchers.

TABLE 1 | Total CITES shipments of live long-tailed macaques and UN Comtrade shipments of live primates from 2010 to 2019 with UN Comtrade values.

\begin{tabular}{cccc}
\hline Year & CITES Exports & UN COMTRADE & Value (US\$) \\
\hline 2010 & 57,113 & 47,659 & $125,305,628.8$ \\
2011 & 41,424 & 37,799 & $106,594,448.3$ \\
2012 & 34,729 & 32,247 & $90,351,157.12$ \\
2013 & 37,179 & 30,893 & $83,741,984.7$ \\
2014 & 46,709 & 46,926 & $131,458,999.8$ \\
2015 & 37,588 & 44,362 & $114,892,027.7$ \\
2016 & 45,309 & 45,563 & $125,644,380$ \\
2017 & 49,535 & 53,176 & $144,226,330.6$ \\
2018 & 69,944 & 62,776 & $157,421,831.6$ \\
2019 & 56,823 & 67,699 & $168,303,018$ \\
Total & 476,353 & 469,100 & $1,247,939,807$
\end{tabular}




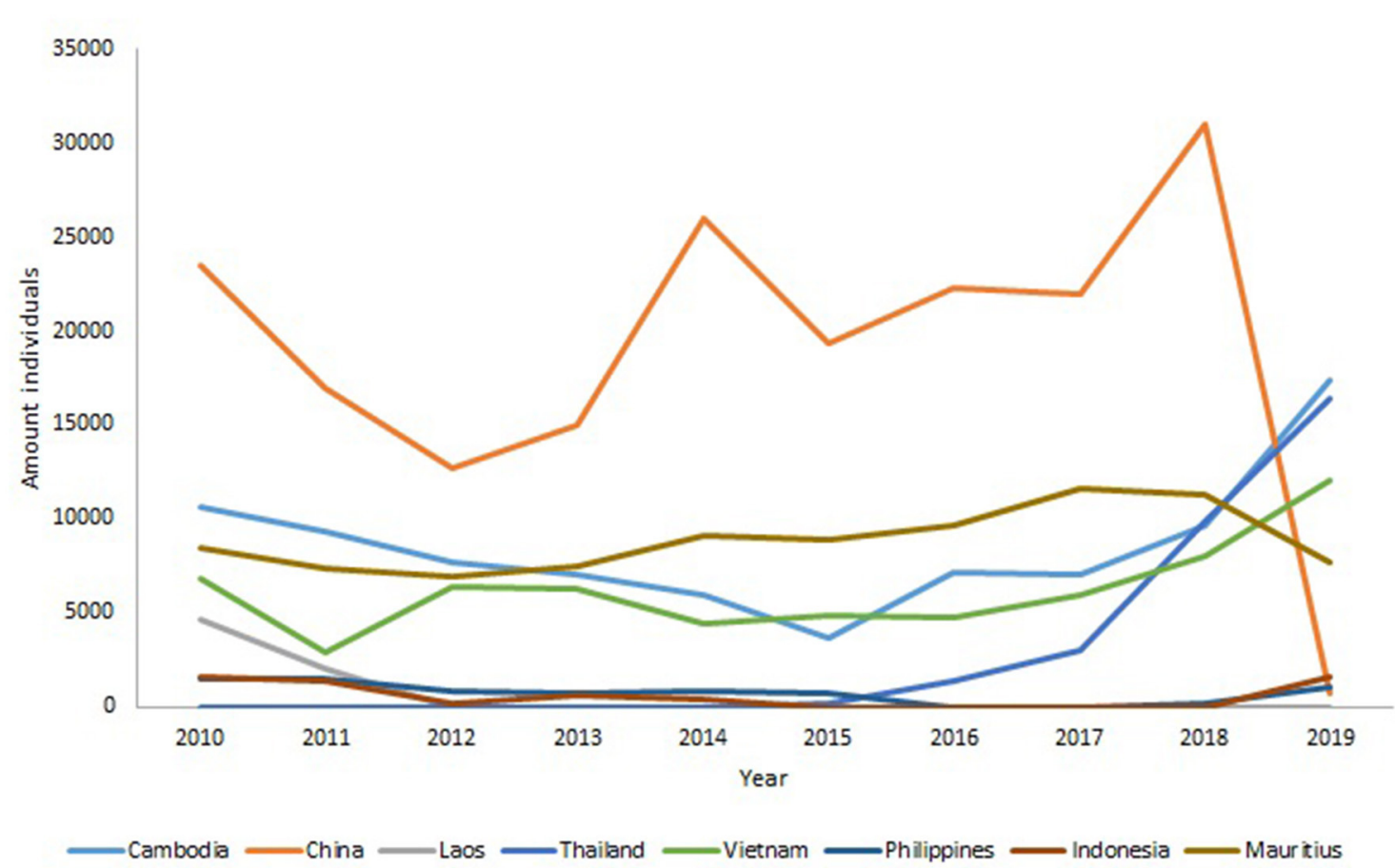

FIGURE 1 | Change in export (as reported by partners) in long-tailed macaques per country from 2010-2019.

Firstly, using the CITES Trade Database, for each of the eight countries listed above, we calculated the proportion of long-tailed macaques of all live primate trade. This ranged between 83 and $100 \%$ (mean $96 \pm 6$ ) thus justifying the use of the live trade in all primates as reported in the UN Comtrade Database.

Our analysis was based on annual data, thus providing us with 80 datapoints (eight countries times ten years) for both the CITES Trade Database and the UN Comtrade Database. Monetary values were available from the UN Comtrade Database only and we divided the total reported value (in US\$) by the units of live primates exported for each year to derive at an unit price for a single primate. Four anomalous values (The Philippines 2012 and 2013, and Thailand 2010 and 2011) were excluded because the UN Comtrade Database provided unrealistic amounts (between 75,000 and 750,000 individuals/year), which were a minimum of 75,000 individuals higher than what the CITES Trade Database reported for that country for that year. We suspect it is due to erroneous data input. All values were corrected for inflation in comparison to December 2019, from which our last datasets are from. We report means \pm standard deviation. Final comparisons were conducted using a Pearson correlation and a scatterplot on log-transformed data was used for visualization. We used R Statistical Software (v4.1.0; R Core Team 2021) for all data analyses.

\section{RESULTS}

Over the ten-year period, the eight countries reported the export of 476,353 live long-tailed macaques, $99.5 \%$ of which

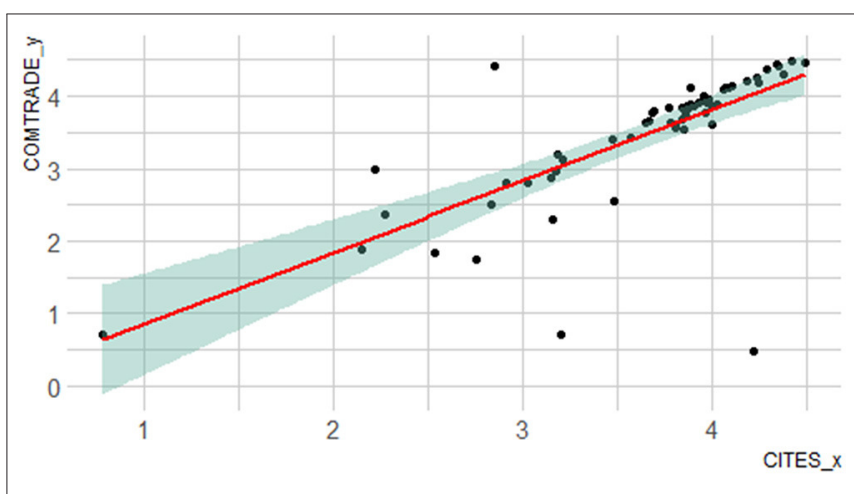

FIGURE 2 | Scatterplot with confidence interval of log-transformed CITES individual Macaca fascicularis shipment data and UN Comtrade live primate units per exporting country from 2010 to 2019.

was declared as either captive-born or captive-bred (Table 1, Figure 1). The number of live primates exported from these same countries listed in the UN Comtrade Database totaled 469,100, suggesting that indeed the vast majority of trade in live primates from this region comprises long-tailed macaques (Table 1).

At the year-on-year country export level, there was a high level of agreement between data reported by the eight countries to CITES and to UN Comtrade ( $\mathrm{R}=0.84, t=11.67, \mathrm{df}=57$, $p<0.0001$; Figure 2).

To calculate the value of the trade in CITES, we multiplied the CITES total export of individual Macaca fascicularis from 
2010-2019 with the average UN Comtrade value/unit live primate over the 10 year period, which was US $\$ 2,672 \pm 267$. Total value of long-tailed macaque trade from 2010-2019: 476,353*2,672= 1,258,026,879 USD.

We encountered three outliers for China in 2019; CITES 703, UN Comtrade 25838, Indonesia in 2019; CITES 1569, UN Comtrade 5, and Thailand in 2019; CITES 16362, UN Comtrade 3.

\section{DISCUSSION}

We investigated the magnitude and monetary value of the longtailed macaque trade by incorporating data from two databases; the CITES Trade Database and the UN Comtrade Database and comparing the data retrieved between the two.

The total value of CITES shipments of live long-tailed macaques from 2010 to 2019 (when multiplied by the UN Comtrade average unit value) was 1,26 billion USD, which is similar to the 1,25 billion USD reported in the UN Comtrade Database (Table 1), although the latter value may include values of more or less expensive primate species than the long-tailed macaque. This comparison indicates that the UN Comtrade report of live primates traded equals the long-tailed macaque trade reported by CITES. The total values (Table 1) of both databases are also comparable, and so are the totals per year per exporting country, where we found a significant positive correlation (see also Figure 2). This means that the reported live primate trade in the UN Comtrade Database resembles the international trade in long-tailed macaques. If legal trade mirrors illegal trade, and for example $28 \%$ is added to the volume of legal trade through confiscations in the US alone (Tittensor et al., 2020), the magnitude we present here only presents a fraction of the true trade. The reports of the Species Survival Commission furthermore discuss that laundering wild-caught long-tailed macaques as captive bred is a reoccurring event indicating that a portion of the legal trade presented here is actually illegal (SSN, 2012, 2015a,b).

We encountered three outliers in our dataset for 2019; China, Indonesia and Thailand. These numbers were double checked one year after the deadline for 2019 reports. We therefore suspect the discrepancies between individual/unit amounts in the two databases to be due to differences in reporting year.

These results show that by combining data from the UN Comtrade and CITES it is possible to determine values in relation to trade in long-tailed macaques. This may well offer the opportunity to perform similar analyses with other species of fauna and flora as reported by CITES parties. Given that the illegal wildlife trade is the $3^{\text {rd }}$ largest source of revenue for global organized crime (Wyatt et al., 2020), the ability to ascertain unit values may well be very useful to evaluate the potential conservation pressure for particular endangered species.

From 2010-2019, China has supplied a large part of the market with long-tailed macaques from both in-country breeding centers and imported individuals from Southeast
Asia (Figure 1). However, in 2019, results showed that China reported a $96 \%$ reduction in exports of long-tailed macaques compared to an average of the previous three years (prior to international awareness of the COVID-19 pandemic). Results also show that other countries that do not historically have breeding centers the size of those in China (Cyranoski, 2016) appeared to have increased exports to satisfy international demand (Figure 1).

The importance of long-tailed macaques for pre-clinical testing has the potential to exert significant pressure on wild populations, particularly because of the unit value per macaque that has been shown in these results. Whilst there has been a long-term trend for pharmaceutical companies to source their requirements from captive bred monkeys raised in farms (Carvalho et al., 2019), there may not be sufficient stock to cope with sustained periods of high demand for live monkeys used in pre-clinical testing procedures (Nature, 2021; Tian, 2021). Ongoing research will seek to determine if the additional (COVID era) demand for long-tailed macaques from the pharmaceutical sector has compromised efforts over the last decade to promote improved protection, better law enforcement and trade regulation regarding illegal wildlife trade (SSN, 2012, 2015a,b). What is clear is that the trade in long-tailed macaques from 2010 to 2019 is a multi-billion dollar industry.

It is crucial to monitor legal trade in wildlife as it provides an idea of illegal trade as well, and because it often thrives unnoticed, which can have detrimental effects on wild populations of the particular species (Andersson et al., 2021). It is clear that the combination of the CITES Trade Database and the UN Comtrade Database provides an unique opportunity to assess the magnitude of wildlife trade, which is crucial for conservation management going forward.

\section{DATA AVAILABILITY STATEMENT}

Publicly available datasets were analyzed in this study. All data are freely available on the databases: CITES Trade Database https:// trade.cites.org/ and UN Comtrade Database https://comtrade.un. org/.

\section{AUTHOR CONTRIBUTIONS}

$\mathrm{MH}, \mathrm{VN}$ and $\mathrm{EB}$ conceptualised the idea. MG collected the data. $\mathrm{MH}$ and $\mathrm{DN}$ analysed the data. All authors contributed to writing the manuscript and have all approved the final version.

\section{FUNDING}

This research was funded by Animal Protection Denmark awarded to MH (Grant No. 0121). The funders had no role in study design, data collection, data analysis, data interpretation, or writing of the report. 


\section{REFERENCES}

Andersson, A. A., Tilley, H. B., Lau, W., Dudgeon, D., Bonebrake, T. C., and Dingle, C. (2021). CITES and beyond: Illuminating 20 years of global, legal wildlife trade. Glob. Ecol. Conserv. 26, e01455. doi: 10.1016/j.gecco.2021.e01455

Badyal, D. K., Modgill, V., and Kaur, J. (2009). Computer simulation models are implementable as replacements for animal experiments. Alternat. Lab. Anim. ATLA 37, 191-195. doi: 10.1177/026119290903700208

Carvalho, C., Gaspar, A., Knight, A., and Vicente, L. (2019). Ethical and scientific pitfalls concerning laboratory research with non-human primates, and possible solutions. Animals (Basel) 9, 12. doi: 10.3390/ani9010012

Chan, H.-K., Zhang, H., Yang, F., and Fischer, G. (2015). Improve customs systems to monitor global wildlife trade. widely used trade codes lack taxonomic granularity. Science 348, 6232. doi: 10.1126/science.aaa,3141

CITES Trade Database (2021). Available online at: https://trade.cites.org/. (accessed September 1, 2021).

Cyranoski, D. (2016). Monkey kingdom. Nature News 532, 7599. doi: $10.1038 / 532300$ a

Estrada, A., Garber, P. A., Rylands, A. B., Roos, C., Fernandez-Duque, E., Di Fiore, A., et al. (2017). Impending extinction crisis of the world's primates: why primates matter. Sci. Adv. 3, e1600946. doi: 10.1126/sciadv.1600946

Fowler, S., Bräutigam, A., Okes, N., and Sant, G. (2021). Conservation, Fisheries, Trade and Management Status of CITES-Listed Sharks. BNF Skripten, 607

Guhad, F. (2005). Introduction to the 3Rs (refinement, reduction and replacement). J. Am. Assoc. Lab. Anim. Sci. 44, 58-59.

Hansen, M. F., Gill, M., Nawangsari, V. A., Sanchez, K. L., Cheyne, S. M., Nijman, V., et al. (2021). Conservation of Long-tailed Macaques: Implications of the Updated IUCN Status and the CoVID-19 Pandemic. Prim. Conserv. 35, 1-11.

Home Office (2017). Annual Statistics of Scientific Procedures on Living Animals Great Britain 2016. Edited by Home Office. London: The National Archives.

Lankau, E. W., Turner, P. W., Mullan, R. J., and Galland, G. G. (2014). Use of nonhuman primates in research in North America. J. Am. Assoc. Lab. Anim. Sci. 53, 278-282.

Nature (2021). The US is Boosting Funding for Research Monkeys in the Wake of COVID. Available online at: https://www.nature.com/articles/d41586-02101894-z. (accessed January 10, 2021).

Nijman, V. (2017). North Africa as a source for European eel following the 2010 EU CITES eel trade ban. Marine Policy 85, 133-137. doi: 10.1016/j.marpol.2017.06.036

Nijman, V., and Healy, A. (2016). "Present-day international primate trade in historical context," in An Introduction to Primate Conservation, eds Wich S and Marshall A. Oxford: Oxford University Press, p. 129-142.

Nijman, V., Nekaris, K. A. I., Donati, D., Bruford, M., and Fa, J. (2011). Primate conservation: measuring and mitigating trade in primates. Endangered Species Res. 13, 159-161. doi: 10.3354/esr 00336
Prior, H., Sewell, F., and Stewart, J. (2017). Overview of 3Rs opportunities in drug discovery and development using non-human primates. Drug Discov. Today Dis. Models. 11, 08. doi: 10.1016/j.ddmod.2017.11.005

SSN (2012). Selection of the long-tailed macaque (Macaca fascicularis) for inclusion in the review of significant trade (resolution conf. 12.8 (rev. cop13). Washington: Species Survival Network. Available onlione at: http://www.ssn.org/Meetings/ ac/ac25/SSN_Macaque_STR.pdf. (accessed October 18, 2017).

SSN (2015a). Illegal trade in long-tailed macaque (Macaca fascicularis) in Cambodia, Lao PDR and Vietnam. Washington: Species Survival Network. Available onlione at: http://www.ssn.org/Meetings/sc/SSN_SC66_Macaque. pdf. (accessed November 1, 2017).

SSN (2015b). Review of Macaca fascicularis in Cambodia and Vietnam Annex ii Lao PDR. Geneva: CITES. Available onlione at: https://cites.org/sites/default/ files/eng/com/ac/28/Inf/E-AC28-Inf-32.pdf. (accessed October 16, 2017).

Tian, C.-J. (2021). China is facing serious experimental monkey shortage during the COVID-19 lockdown. J. Med. Primatol. 21, 12528. doi: 10.1111/jmp.12528

Tittensor, D. P., Harfoot, M., McLardy, C., Britten, G. L., Kecse-Nagy, K., Landry, B., et al. (2020). Evaluating the relationships between the legal and illegalinternational wildlife trades. Conserv. Lett. 13:e12724. doi: $10.1111 /$ conl.12724

UN Comtrade (2021). Available onlione at: https://comtrade.un.org/data. (accessed September 1, 2021)

Wells, D. J. (2011). Animal welfare and the 3Rs in European biomedical research. Annal. New York Acad. Sci. 1245, 14-16. doi: 10.1111/j.1749-6632.2011.06335.x

Wyatt, T., van Uhm, D., and Nurse, A. (2020). Differentiating criminal networks in the illegal wildlife trade: organized, corporate and disorganized crime. Trends Organiz. Crime 23, 350-366. doi: 10.1007/s12117-020-09385-9

Conflict of Interest: The authors declare that the research was conducted in the absence of any commercial or financial relationships that could be construed as a potential conflict of interest.

Publisher's Note: All claims expressed in this article are solely those of the authors and do not necessarily represent those of their affiliated organizations, or those of the publisher, the editors and the reviewers. Any product that may be evaluated in this article, or claim that may be made by its manufacturer, is not guaranteed or endorsed by the publisher.

Copyright (c) 2022 Hansen, Gill, Briefer, Nielsen and Nijman. This is an open-access article distributed under the terms of the Creative Commons Attribution License (CC $B Y)$. The use, distribution or reproduction in other forums is permitted, provided the original author(s) and the copyright owner(s) are credited and that the original publication in this journal is cited, in accordance with accepted academic practice. No use, distribution or reproduction is permitted which does not comply with these terms. 